
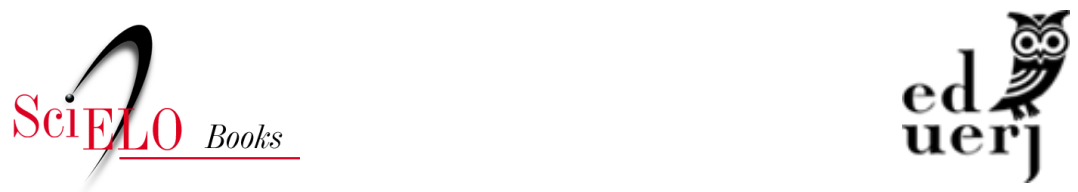

\title{
5. A ilha da chuva e do vento: notas sobre um romance canônico
}

\author{
Vanessa Massoni da Rocha
}

\section{SciELO Books / SciELO Livros / SciELO Libros}

ROCHA, V. M. A ilha da chuva e do vento: notas sobre um romance canônico. In: Tradução em (ent)revista: Simone Schwarz-Bart e as tradutoras brasileiras [online]. Rio de Janeiro: EDUERJ, 2021, pp. 43-49. Letras UERJ collection. ISBN: 978-65-991111-5-0. https://doi.org/10.7476/9786599111150.0005.

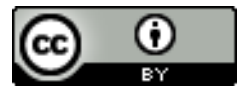

All the contents of this work, except where otherwise noted, is licensed under a Creative Commons Attribution 4.0 International license.

Todo o conteúdo deste trabalho, exceto quando houver ressalva, é publicado sob a licença Creative Commons Atribição 4.0.

Todo el contenido de esta obra, excepto donde se indique lo contrario, está bajo licencia de la licencia Creative Commons Reconocimento 4.0. 


\section{A ilha da chuva e do vento: notas sobre um romance canônico}

O parágrafo inicial do romance, de 1972, configura o que podemos chamar, sem receio de exageros, de obra-prima da literatura antilhana. Citado exaustivamente por críticos e pesquisadores, ele apresenta a força da personagem Télumée Milagre, mulher corajosa, que não se deixa oprimir pelos sucessivos revezes de sua vida:

A terra depende quase sempre do coração do homem: é minúscula se o coração for pequeno, é imensa se o coração for grande. A pequenez da minha terra nunca me afligiu, e nem por isso tenho a pretensão de possuir um grande coração. Se pudesse escolher, seria aqui mesmo na Guadalupe que eu gostaria de nascer, sofrer e morrer. E, no entanto, não há muito, meus avós ainda eram escravos nesta ilha de vulcões, de ciclones e mosquitos, de mentalidades estreitas. Mas não vim ao mundo para sopesar toda a tristeza da terra. Em vez disso, prefiro sonhar, mais e mais, de pé no meio 
do meu quintal, como costumam fazer todas as velhas da minha idade, até que a morte me apanhe em meu sonho, na plenitude da minha alegria... (Schwarz-Bart, 1986, p. 9).

O romance narra a saga de quatro mulheres da família Lougandor: Minerve, Toussine, Victoire e Télumée, colocadas em cena em todas as suas virtudes e fraquezas. A saga da família traz à tona visões diferentes sobre o papel feminino ao longo do tempo. Apesar das especificidades que acompanham as matriarcas, Schwarz-Bart apresenta a personagem Télumée como alguém que, "durante toda a sua vida, tentará continuar essa linhagem de mulheres talentosas, negras de fato, decididas a não se deixarem embaraçar pela vida" (1986, p. 61). É importante precisarmos que Télumée terá uma filha adotiva, Sonore, sendo a única Lougandor a não experimentar a gravidez. As histórias dessas mulheres se imbricam às transformações da sociedade guadalupense ao longo de sua história: a escravizada Minerve teve na abolição da escravatura uma salvação para as investidas libidinosas de seu proprietário. Por sua vez, a bisneta Télumée personifica as desigualdades sociais e as dificuldades econômicas que assolam as gerações que se sucederam ao período escravagista. Por certo, é possível afirmar que Guadalupe se erige como personagem central da obra de Schwarz-Bart, "terra perdida que precisava tanto ser amada” (Schwarz-Bart, 1986, p. 207), departamento entoado em cores vibrantes, na natureza de tirar o fôlego e nos moradores resilientes. As práticas religiosas, as lendas, a musicalidade, a gastronomia, as relações familiares, o vínculo com o espaço e as heranças do sistema colonial e da escravidão se apresentam igualmente como temáticas incontornáveis no romance.

O pesquisador Mouhamadou Cissé considera que Simone Schwarz-Bart "constrói heroínas dominadas, mas que recusam sua condição" (2014, p. 18). Segundo o crítico, entre os adjetivos feminista e feminino, "o feminino se aplica melhor à resistência da autora em razão de seu discurso e de sua postura" (2014, p. 18). Nesse sentido, 
reconhecemos o romance como narrativa na qual há o protagonismo de vozes do feminino, que encontraram na narradora Télumée e nas peripécias de quatro gerações da sua família, uma maneira de mostrar um olhar das mulheres acerca da identidade em Guadalupe.

O romance se organiza em duas partes de estrutura desigual: a primeira, "apresentação dos meus", possui um pouco mais de trinta laudas, enquanto a segunda, "história da minha vida", estende-se por mais de duzentas e se subdivide em quinze capítulos. Em ambas as partes, Télumée procura se colocar face a face com suas progenitoras em um grande exercício de compreensão de si mesma. Por meio de aproximações e afastamentos, o quarteto feminino povoa toda a obra e reitera a máxima do resíduo proposta por Drummond, segundo a qual "de tudo fica um pouco" (Andrade, 1984, p. 93): um pouco de nós nos outros, um pouco dos outros em nós mesmos, um pouco dos objetos, um pouco dos lugares, um pouco dos odores, um pouco das lembranças.

Nesse sentido, não é possível considerarmos o romance como a instituição de uma voz feminina que se elevaria contra seu silenciamento. Não se trata de um discurso uníssono representativo de todo um grupo. Embora a maior parte do romance seja a autobiografia romanceada de Télumée redigida em primeira pessoa, nele habitam vozes variadas que refletem as vicissitudes de distintas épocas, personalidades e histórias. Marcado por lembranças, o discurso telumeano se inscreve no fluxo de memórias e na sua imaginação em costurar narrativas diversas. O interesse da narrativa "não reside no 'que se passa' mas no 'como se passa”' (Heckenbach, 1998, p. 41). Como destaca Heckenbach (1998, p. 41), em seu artigo sobre o discurso antilhano no feminino, "a transformação dos personagens motiva mais os textos que suas ações. [...] O texto feminino sublinha o aspecto negativo de 'ação' e valoriza o 'não evento'”.

No que tange à gênese do romance, Simone Schwarz-Bart (apud Spear, 2013) explica se tratar de "um livro escrito no exílio. Nasceu do 
luto de uma velha amiga, Stephanie Priccin, enquanto eu estava longe dela. E essa nostalgia dupla me levou à página em branco". Acerca do nome da protagonista, Télumée Milagre, Simone revela que, "na realidade, não é sua vida, mas uma compilação de momentos privilegiados, de momentos da sua infância; é uma espécie de memória que quis reconstituir... Télumée é minha madrinha. Milagre, eu acrescentei” (Toumson, 1979, p. 15). E acrescenta: "era uma mulher exaltada, que sentia que o que tinha vivido tinha um sentido. Ela não transmitia uma impressão de banalidade. Não era uma 'aristocrata' no sentido crioulo... ela tinha o sentimento de que ela era um indivíduo único. Essa geração tinha uma percepção aguda de sua dignidade" (Toumson, 1979, p. 15). Dessa forma, tanto no âmbito da intriga romanesca quanto no âmbito da concepção da obra, Pluie et vent sur Télumée Miracle se inscreve num desejo reiterado de conceber um palimpsesto de vozes femininas.

Kathleen Gyssels reconhece o discurso feminino como "vetor da identidade feminina" (1996, p. 4) e acrescenta que "não somente a identidade feminina é tributária da relação mãe-filha, mas também o discurso das mulheres é a força motora para os fatos e para as ficções da filha, e esses discursos, por sua vez, são legados dos ancestrais" (1996, p. 4). São, todos estes discursos, fios que se tecem entre as diversas gerações e que apontam para convergências, memórias identitárias que não cessam de se reinventar e de se reinscrever. A partir da premissa de que "na cultura oral das Antilhas, é a palavra feminina que veicula todo o saber de um povo" (Pieters, 2013, p. 15), o romance concede às heroínas o reconhecimento por serem fontes da memória coletiva.

Como evidencia o título do romance, Télumée é uma dessas mulheres expostas às intempéries da chuva e do vento, aos revezes da vida. Graças à perseverança e à coragem para suportar, que demonstra com afinco, a personagem encarna a força feminina entoada no poema célebre "Assim eu me levanto" (1978), da escritora e ativista negra norte- 
-americana Maya Angelou (2020, p. 176): “Abandonando as noites de terror e medo / Eu me levanto / Para um amanhecer maravilhosamente claro / Eu me levanto / Trazendo as dádivas que meus ancestrais me deram, / Eu sou o sonho e a esperança dos escravos. / Eu me levanto / Eu me levanto / Eu me levanto". Trata-se dessas mulheres sofridas que podem ser comparadas à cana nas plantações, que chega a envergar durante as tempestades, mas se reergue e dá frutos, apesar das provações. A resiliência assume, dessa forma, grande faceta em sua trajetória: ela suportará o abandono materno, a violência doméstica, as paixões sofridas, a doença, a loucura do primeiro marido, a ausência de filhos legítimos, a inveja das vizinhas, a morte da avó e os mistérios com o além, como o episódio em que vence o anjo Médard e assume, diante da comunidade, o epíteto de milagreira.

Em grande contraste às chuvas e aos ventos, que representam as inúmeras intempéries que acometeram a família Lougandor e que figuram no título do romance, o trecho de abertura deste traz à cena a supremacia do sol como símbolo-maior da força, da simbiose antilhana com a natureza e como presente à narradora no momento de seu descanso e no caminho para o reencontro com seus ancestrais. Por meio dessa saga feminina, Simone Schwarz-Bart concede às mulheres seu lugar ao sol no palimpsesto de histórias capazes de erguer os complexos pilares da identidade crioula, preenchendo as lacunas denunciadas por Spivak (2014, p. 85) em seus estudos sobre o discurso dos subalternos: "se, no contexto da produção colonial, o sujeito subalterno não tem história e não pode falar, o sujeito subalterno feminino está ainda mais profundamente na obscuridade".

No incontornável manifesto Éloge de la créolité (1989), que já mencionamos brevemente, os escritores e ensaístas martinicanos Patrick Chamoiseau, Raphaël Confiant e Jean Bernabé, este último também renomado linguista, dedicam-se a inventariar os temas e premissas a serem levados em conta pelos intelectuais antilhanos em suas produções. Inscritos no desejo de manifestar a crioulidade 
na tessitura artística, de um modo geral, e na literária, de maneira mais específica, eles defendem o "princípio de que não existe nada no mundo que seja pequeno, pobre, inútil, vulgar, inapto a enriquecer um projeto literário. Nós fazemos corpo com nosso mundo. Nós queremos, na verdadeira crioulidade, nomear cada coisa do mundo e dizer que ela é bonita" (Bernabé et al., 2015, p. 39-40). Segundo os escritores, a escrita deve:

aceitar sem divisões nossas crenças populares, nossas práticas mágico-religiosas, nosso realismo maravilhoso. [...] Escutar nossa música e experimentar nossa cozinha. Buscar como vivemos o amor, o ódio, o espírito que temos da melancolia, nossos modos na alegria e na tristeza, na inquietude e na audácia. Buscar nossas verdades. Afirmar que uma das missões dessa escrita é dar voz aos heróis insignificantes, aos heróis anônimos, aos esquecidos da crônica colonial, aos que levaram uma resistência plena em desvios e em paciências, e que não correspondem em nada à imagem do herói ocidental-francês. [...] Viver, reviver, fazer viver tudo isso intensamente, tremer com os calafrios, palpitar onde isso palpita, percorrer nossa geografia interna para melhor percebê-la e compreendê-la (2015, p. 40-41).

Nessa perspectiva, compreendemos as razões que levaram o escritor Patrick Chamoiseau a considerar o romance uma obra da crioulidade avant la lettre. De fato, mais de uma década antes da publicação do manifesto, importante pilar da identidade cultural e literária antilhana, Simone Schwarz-Bart presenteia o público antilhano com uma verdadeira ode às artes de dizer e de fazer do povo guadalupense, uma obra inegavelmente de vanguarda. A capacidade ímpar do romance em exaltar e espelhar a realidade crioula explica a importância da obra na formação literária de gerações e mais gerações de leitores, as numerosas pesquisas acadêmicas e publicações centradas na obra e as inúmeras traduções do romance. 
Traduzido em mais de doze línguas e laureado, em 1973, com o Grande Prêmio das leitoras de Elle, o romance se tornou a obra de maior repercussão da escritora. A tradução para o português, feita por Estela dos Santos Abreu, foi publicada em 1986. 